\title{
Social Justice Metrics for Libraries: Considerations for an Emerging Framework
}

\author{
Lisa Janicke Hinchliffe \\ University of Illinois at Urbana-Champaign, USA
}

The mission of the academic institution to support student learning and success has embedded within it the need to attend to issues of equity, inclusion, and justice. By providing a shared collection for access by all members of a community, the academic library seeks to establish a shared level of access to information. At one level, this seems to create equality inherently; however, it is obvious that not everyone is equally able to avail themselves of this access. Differences in resources, preparation, and experiences mean that equal access does not guarantee equitable access. If an academic library turns its attention to equity, it will develop additional services and offer further resources, likely targeted to particular segments of its community.

While much work has been done to identify library operations and activity metrics as well as metrics of impact on student learning and success, little attention has been given to identifying potential metrics for library contribution to social justice efforts. Moreover, academic institutions likely have as part of their mission community engagement and social development, and libraries will also contribute to this public effort. This paper seeks to begin to fill the gap in the assessment practice relative to social justice by offering approaches to thinking about potential metrics for consideration as well as ideas for methods and strategies for gathering and analyzing data as evidence related to those metrics.

\section{Frameworks for Metrics}

The most common frameworks for identifying metrics for academic libraries are:

- IPEDS: Integrated Postsecondary Education Data System (http://nces.ed.gov/ipeds)-The Academic Library component of this service from the US Department of Education's National Center for Education Statistics reports data on library resources, services, and expenditures at degree-granting postsecondary institutions.

- ACRL Trends \& Statistics Survey (http://acrl.libguides.com/stats/surveyhelp)-Data from this annual survey are published through ACRL Metrics (https://www.acrlmetrics.com/) and cover expenditures, expenses, staffing, collections, and services. The survey includes current IPEDS data points, as well as data points that were previously collected by IPEDS but have been discontinued and annual questions to probe into current trends.

- ARL Statistics \& Salary Surveys (https://www.arl.org/arl-statistics-salary-survey/)-Annual data on collections, expenditures, staffing, and services of the members of the Association of Research Libraries.

- The Standards for Libraries in Higher Education (http://www.ala.org/acrl/standards /standardslibraries)-Appendix 2: Benchmarking and Peer Comparison of this document from the Association of College and Research Libraries identifies potential metrics for each of the standards.

In addition, the AiA findings provide a framework for considering library metrics related to library impact on student learning and success. Specifically, an academic library can document its activities and connect them to the findings from AiA that:

1. Students benefit from library instruction in their initial coursework.

2. Library use is related to student success. 
3. Collaborative academic programs and services involving the library enhance student learning.

4. Information literacy instruction strengthens general education outcomes.

5. Library research consultations boost student learning. ${ }^{1}$

In addition to these frameworks from the library sector, two additional projects can also inform thinking about social justice metrics from libraries:

- HuMetricSSS: Humane Metrics Initiative (https://humetricshss.org/)-This project focused on examining humane indicators of excellence in academia, with particular attention to the humanities and social sciences, in order to develop a values-based framework for assessing scholars. The values identified are collegiality, quality, equity, openness, and community.

- Carnegie Foundation's Classification for Community Engagement (https://www.brown.edu/swearer/carnegie)-This voluntary classification identifies data points for documenting an institution's collaboration with its larger communities in knowledge and resource exchange.

\section{Towards a Social Justice Metrics for Libraries Framework}

Over the past year, a small group has been holding monthly discussions about the possibility of developing a framework for social justice metrics. The small group came together under the leadership of Sarah Pickle, director of organizational planning and assessment at the Claremont Colleges library, who solicited interest through a post to the ARL-ASSESS email list, and has pursued the discussion through a democratic and nonhierarchical dialogue, as befitting the conversation topic.

A consensus has emerged that social justice metrics are possible to identify and articulate; however, doing so in local context has proven a more achievable approach for now than developing a universal framework. ${ }^{2}$ The community discussion has also demonstrated that there is great interest in and enthusiasm for identifying social justice metrics in libraries and a shared view that a more formal (and perhaps funded) process is needed to attain the envisioned social justice metrics framework. If a social justice metrics framework is developed, it could be used for reflection/examination of current practices, inspiration for library development, planning, diagnosing challenges and problems, and organizational benchmarking. It is open to debate whether such a framework could-or should-be used for ranking.

\section{Conclusion}

This paper does not present a definite approach to social justice metrics for academic libraries nor does it claim to fully detail the considerations. Instead, it seeks to begin to suggest a framework for how this task of identifying social justice metrics might be approached and offers an invitation for additional partners in this community conversation. To join the dialogue, contact Sarah Pickle (sarah.pickle@claremont.edu).

\section{-Copyright 2019 Lisa Janicke Hinchliffe}

Lisa Janicke Hinchliffe

Professor/Coordinator for Information Literacy Services and Instruction

University Library, University of Illinois

1408 West Gregory Drive, Urbana, Illinois 61801

217-333-1323, ljanicke@illinois.edu 


\section{References}

1. K. J. Malenfant and K. Brown, Creating sustainable assessment through collaboration: A national program reveals effective practices, Occasional Paper No. 31, Urbana, IL: University of Illinois and Indiana University, National Institute for Learning Outcomes Assessment, 2017.

2. See papers by Cameron Tuai and Krystal Wyatt-Baxter in these proceedings as examples of two different local approaches. 